\title{
INDUÇÃO DE ESTRUTURAÇÕES ESFÉRICAS OU SIMILARES DURANTE A CRIŞTALIZAÇÃO DA ÁGỦA POR PROCESSOS FÍSICOS OU QUíMICOS
}

\author{
Induction of spherical or similar structures during the water crystallization \\ by physical or chemical process
}

Fabiano de Carvalho ${ }^{1}$

\begin{abstract}
RESUMO
Estruturar cristais de gelo é atrativo devido à possibilidade de diminuir os danos causados pelo congelamento ao mínimo. A ocorrência de agulhas ou esqueletos danosos às células significa que foram desiguais os crescimentos das faces do cristal. Objetivouse com este trabalho induzir a formação de sementes cristalinas menores, arredondadas ou com alto grau de simetria, para aumentar a probabilidade de crescimentos geometricamente semelhantes à forma original e que elimine crescimentos desiguais nas faces do cristal de gelo. Foram usadas: 1) substâncias anfifílicas, para afetar a estruturação cristalina habitual da água e 2) substâncias com a possibilidade de formação de ligações de hidrogênio nas diversas direções e formar arranjos simétricos. Sob a influência do dodecil sulfato sódico (SDS), um tensoativo, os cristais de gelo cristalizaram na forma de agregados cristalinos esféricos. Cristais esferulíticos foram obtidos sob a influência dos aminoácidos valina, histidina, glicina e do sal sulfato de alumínio e amônio. Cristais poliédricos com faces curvas foram conseguidos sob a influência dos tensoativos Triton ® X 100, Tween ® 80 e de um sal biliar (ácido quenodeoxicólico). $\mathrm{O}$ melhor resultado foi obtido sob a influência da floroglucina. Esse trifenol produziu cristais pequenos, com extremidades arredondadas e em todas as camadas da amostra.
\end{abstract}

Termos para indexação: Criopreservação, cristalização, estruturação de cristal de gelo, substâncias anfifílicas.

\begin{abstract}
The possibility of ice crystal structuring is attractive because it is possible to reach some structures of reduced dimensions capable of decrease the freezing damage to the minimal. The occurrences of needles or skeletons harmful to the frozen tissues demonstrate that the crystal face grown were unequal. The objective of the research is to the induce formation of smaller crystalline seeds, spherical or with a high symmetry level to increase the probability of original form. It was used: 1) anphiphilic substances, to affect the usual crystalline structure of the water; 2) substances with hydrogen bond possibility containing water in all directions in order to arrange symmetrical structures. Under the influence of sodium dodecyl sulfate (SDS), a surface-active agent, the ice crystals composed of spherical crystalline aggregates. Spherulitic crystals were obtained under the influence of valina amino acid, histidine, glicine and salt sulfate aluminum and ammonia. Polyhedric crystals with curve faces were obtained with the influence of the surfaceactive agent Triton ${ }^{\circledR}$ X 100, Tween ${ }^{\circledR} 80$ and of the bile salt the quenodeoxicolic acid. The best result was obtained under the influence of phoroglucine. This of the triphenol was capable of producing small crystals with rounded extremities and in all stratum of the sample. In all the order solutions the spherical crystals appears in the superior stratum only.
\end{abstract}

Index terms: Cryopreservation, crystallization, ice structure, anphiphilic substances.

(Recebido em 3 de dezembro de 2004 e aprovado em 9 de setembro de 2005)

\section{INTRODUÇÃO}

Entre o numeroso elenco de processos de preservação, o congelamento é o que melhor mantém as características organolépticas e nutricionais similares às do produto fresco, suas alterações são menores do que qualquer outro método. Mesmo assim, nem sempre é possível manter uma integridade celular e a textura do produto congelado; é que a água congelada tem um comportamento peculiar: expande-se ao cristalizar e, ao fundir-se, tem a tendência de recristalizar, de aglutinar, formando longos e protundentes cristais de gelo. Estes cristais, agulhas como são chamados, geram uma série de danos mecânicos, bioquímicos e osmóticos aos tecidos. O efeito é altamente prejudicial e compromete a qualidade dos produtos.
Há dois mecanismos que podem promover dano à estrutura celular e conduzir diretamente a uma diminuição da firmeza do tecido. O primeiro está relacionado com a possibilidade de perfuração de membranas celulares pelo cristal de gelo intracelular. $\mathrm{O}$ segundo se relaciona com a quebra da parede extracelular e abre caminho para o colapso das células (CARNEIRO \& CAL-VIDAL, 1992, 1998; RESENDE \& CAL-VIDAL, 1997).

Uma preservação congelada eficiente deve evitar a formação de grandes cristais de gelo sem que haja uma remoção de água - um reagente essencial no metabolismo celular e seus mecanismos de manutenção; e importante por fornecer um ambiente favorável para as interações hidrofóbicas que mantém as estrutura das membranas. 
A ocorrência de grandes cristais de gelo, ou agulhas, significa que foram desiguais as oportunidades para o seu crescimento. Os cristais menos danosos são (em princípio) aqueles com muitas faces equivalentes, onde as oportunidades de crescimento são iguais nas diversas direções.

Durante o congelamento de soluções aquosas a fase não congelada muda significativamente as propriedades físico-químicas, tensão superficial e interfacial. A dissociação de substâncias anfifílicas na água (do grego: amphi = "nos dois lados"; philos = "forte afinidade", "atração"), cuja estrutura simples é constituída de afinidades opostas com a água - uma parte polar, conhecida como "cabeça hidrofílica" (hidro = "água" + filica = "amizade") e outra apolar, conhecida como "cauda hidrofóbica" (fóbico = "medo") —, provoca um fenômeno de auto construção em soluções aquosas. Uma força, o efeito hidrofóbico, agindo principalmente nas regiões interfaciais (interface cadeia hidrocarbônica / água) tende a diminuir o contato com a água blindando a porção hidrofóbica (hidratação hidrofóbica). Estas interações hidrofóbicas (ECHLIN, 1992) - mais favoráveis-, modificam a estruturação estrita da água durante a sua cristalização porque diminuem o número de ligações de hidrogênio por unidade de volume (GARRETT \& GRISHAM, 1995).

Com este trabalho, fez-se investigações na tentativa de encontrar substâncias com poder de modificar a disposição das moléculas d'água, do estado cristalino habitual para cristalizações esféricas; ou capazes de formar sementes cristalinas com a possibilidade de produzir estruturas moleculares simétricas menos protundentes adequadas para reduzir (ao mínimo) os danos celulares originados pelo congelamento. E ainda, monitorar essas estruturações com o uso de microscopia ótica para estabelecer a influência das substâncias na estruturação e morfologia dos cristais de gelo nas soluções modelo.

\section{MATERIAL E MÉTODOS}

Foram testadas as seguintes substâncias:

1) substâncias anfifílicas: os tensoativos: SDS (dodecil sulfato sódico), Triton ${ }^{\circledR}$ X 100, o ácido quenodeoxicólico (um sal biliar) e Tween @ 80 e os aminoácidos: histidina, valina e glicina;

2) substâncias com possibilidade de formar ligações de hidrogênio: floroglucina e sulfato de alumínio e amônio.

Os anfifilos foram usados para se adsorverem nas interfaces (ar/água e gelo/água). A adsorção em superfícies sólidas desfavorece a taxa de transferência de massa d'água para os germes cristalinos e a agregação de cristais próximos entre si e, como conseqüência, reduz o crescimento das sementes cristalinas (ou até mesmo, o paralisa).

A floroglucina e o sulfato de alumínio e amônio foram testados como estruturantes. São moléculas com múltiplas possibilidades de reação com a água em regiões geometricamente precisas e bem distribuídas no espaço. Aumentam o número de possibilidades de formar arranjos atômicos simétricos e, conseqüentemente, sementes cristalinas esféricas capazes de tornar possível um crescimento cristalino semelhante.

Foram testadas várias concentrações de soluto para mudar a estrutura habitual da água e afetar a velocidade de difusão das moléculas até a superfície do gelo.

Nos experimentos envolvendo tensoativos, todas as concentrações testadas foram acima da concentração crítica micelar (CMC), na qual são formados espontaneamente agregados moleculares termodinamicamente estáveis (SILVA, 1997).

\section{Preparação e congelamento de soluções modelo}

Todas as soluções modelo foram preparadas diluindo-se as diversas substâncias em água destilada em diferentes concentrações (Tabela 1). Após serem homogeneizadas, $3,5 \mathrm{~mL}$ das soluções foram colocadas em placas de Petri $(250 \mathrm{~mm}$ de diâmetro por $150 \mathrm{~mm}$ de altura) devidamente etiquetadas e, em seguida, tampadas. Alguns minutos após o seu preparo, as amostras foram levadas ao congelador (Metal Frio, São Paulo-Brasil) e

TABELA 1 - Substâncias empregadas nas soluções modelo submetidas ao congelamento.

\begin{tabular}{lc}
\hline Substâncias & Concentrações \\
\hline Valina (Merck) & $1,0 \% ; 1,5 \% ; 2,0 \% ; 3,0 \%$ e \\
Histidina (Merck) & $0,15 \%$ e $0,20 \%$ \\
Glicina (Synth) & $7 \% ; 10 \% ; 15 \%$ e $30 \%$ \\
Floroglucina (Merck) & $0,15 \% ; 0.20 \% ; 0,50 \% ;$ \\
Sulfato de Alumínio e & $1,0 \% ; 1,5 \%$ e $3,0 \%$ \\
Amônio (Quimibrás) & $0,15 \% ; 0,25 \% ; 0,50 \% ;$ \\
SDS (Merck) & $1,0 \% ; 2,0 \%$ e $3,0 \%$ \\
Sais biliares (Merck) & $0,25 \% ; 1,0 \% ; 1,5 \%$ e $5,0 \%$ \\
Triton ® X-100 & $0,25 \% ; 0,5 \% ; 1,0 \%$ e $5,0 \%$ \\
(Merck) & $1,0 \%$ e $2,0 \%$ \\
Tween $® 80$ (Merck) & \\
\hline
\end{tabular}


deixadas por mais de 2 horas para serem congeladas (em ar estático) - atingindo uma temperatura aproximada de $20^{\circ} \mathrm{C}$. Todo o experimento foi feito em duplicata.

\section{Microscopia óptica}

Depois de congeladas, as amostras foram destampadas e levadas para o microscópio óptico de contraste de fase (Nikon optiphot phase contrast 1.25, Japão), munido de um sistema de câmera automático (Nikon FX-35A) e filtro polarizador (Olympus U-Pot, Japão). As imagens das estruturas cristalinas (ampliadas 400 vezes) foram observadas. Entretanto, nem todas as amostras reuniram condições que permitisse um registro fotográfico verdadeiro - devido ao processo de fusão à temperatura ambiente, que inicia aproximadamente 30 segundos após terem sido removidas do congelador. As que reuniram foram fotomicrografadas.

\section{RESULTADOS E DISCUSSÃO}

\section{Estruturação dos cristais de gelo na água destilada}

Os cristais fotomicrografados na água destilada congelada $\left(-20^{\circ} \mathrm{C}\right)$ apresentam uma estruturação hexagonal, mas com algumas distorções (comuns em todos os cristais). No entanto, são mantidos na sua maioria os vértices com ângulos de $120^{\circ}$ (Fig. 1A).

\section{Desvios da simetria hexagonal}

Nem sempre os cristais de gelo cristalizam na forma hexagonal prismática, mas em forma de feixes radiais. Sob a influência do dodecil sulfato sódico (SDS) a $2 \%$ nota-se que a estrutura resultante pode ter a sua origem de núcleos diferentes, que cresceram simultaneamente em forma de agulha com crescimentos radiados preenchidos de modo a originar uma forma esférica (ou micelar, como é chamada) (Fig. 1B).

Cristais poliédricos com faces curvas foram conseguidos sob a influência dos tensoativos Triton ${ }^{\circledR} \mathrm{X}$ 100 a $0,25 \%$ (Fig. 1C), Tween ${ }^{\circledR} 80$ a $2 \%$ (Fig. 1D) e do sal biliar (ácido quenodeoxicólico) 5\% (Fig. 2E).

Soluções contendo os aminoácidos glicina 10\% (Fig. 2F), valina $5 \%$ (Fig. 2G), histidina $0,15 \%$ (Fig. $2 \mathrm{H}$ ), o sal sulfato de alumínio e amônio $0,30 \%$ (Fig. 2I) e o trifenol floroglucina $0,5 \%$ (Fig. 2J), mostram que a inteira estrutura micelar se originou de um núcleo individual, que se espraiou pelas extremidades formando feixes com crescimentos que conduziram a uma armação esférica.

O melhor resultado foi observado na influência do trifenol floroglucina (ou floroglucinol), que produziu pequenas e arredondadas estruturações não só na superfície, mas também nas camadas inferiores da água congelada.
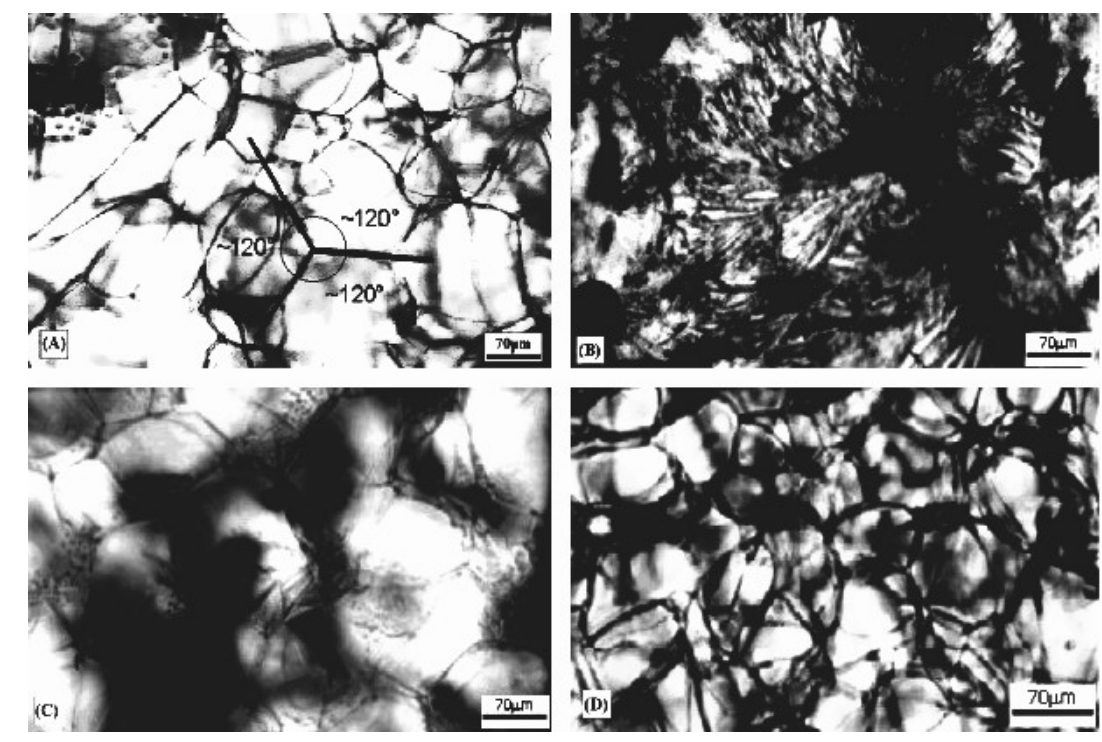

FIGURA 1 - Estruturação no gelo: A) na água destilada, B) sob a influência do dodecil sulfato sódico (SDS) $2 \%$, C) do Triton ${ }^{\circledR}$ X100 0,25\%, D) do Tween ${ }^{\circledR} 802 \%$.

Ciênc. agrotec., Lavras, v. 31, n. 3, p. 814-820, maio/jun., 2007 
Algumas fotomicrografias apresentaram no centro da arquitetura micelar uma superfície com muitas e pequenas protuberâncias, cujo contorno mostra ressaltos de onde partem finas agulhas. É muito provável que esses ressaltos tenham sido provocados por anfifilos que se adsorveram nas superfícies sólidas dos pequenos e arredondados sistemas cristalinos constituídos por um comprimido conjunto de cristais de gelo poliédricos (Fig. 3).

Levantaram-se duas possíveis razões para os desvios da simetria hexagonal e a formação das estruturas micelares na camada superficial.

A primeira, é que o calor de cristalização é absorvido mais rápido e intensamente pelo ar. Assim, é natural que a nucleação se inicie na superfície, onde o congelamento é relativamente rápido.
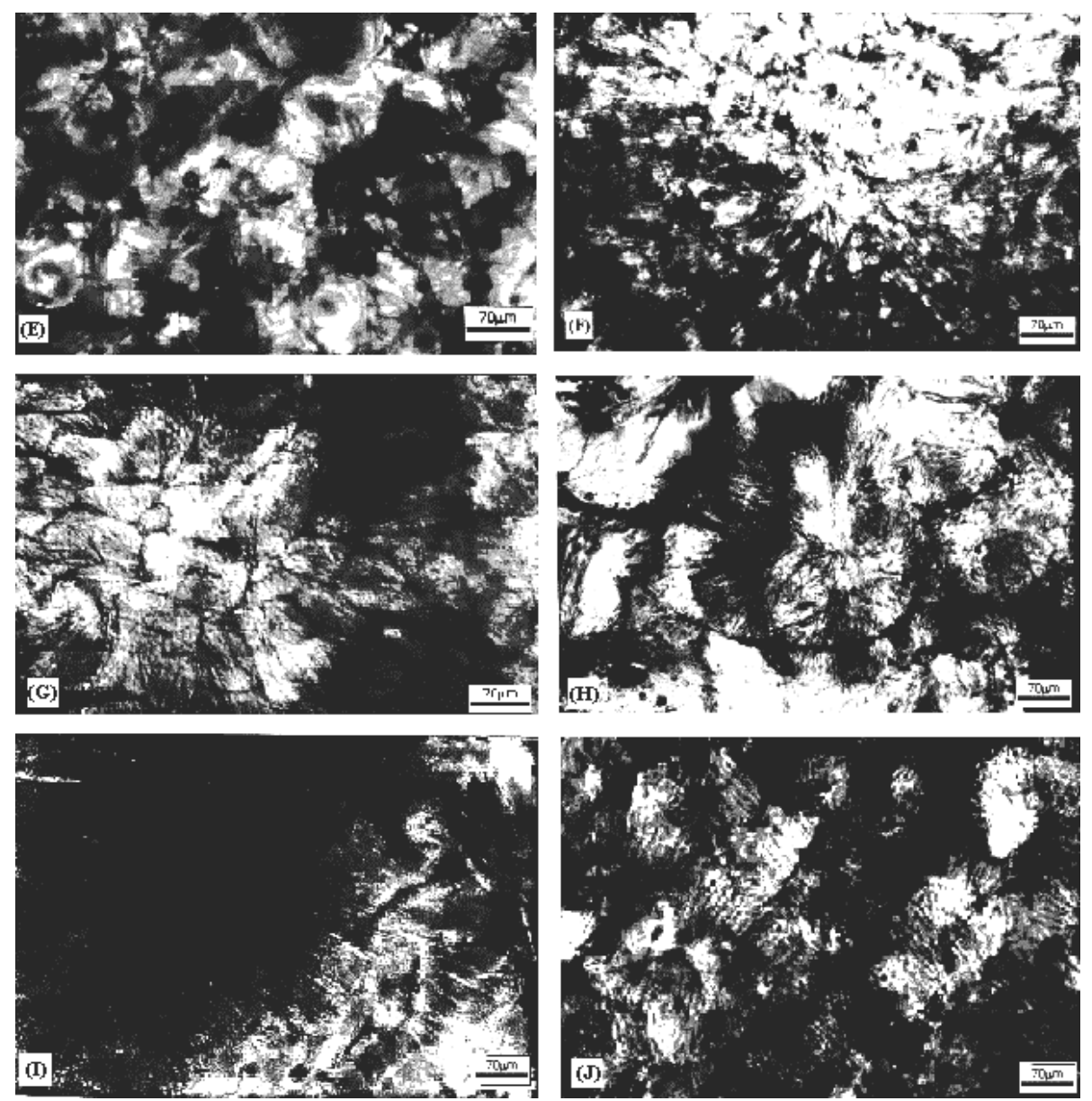

FIGURA 2 - Estruturação no gelo: E) do ácido quenodeoxicólico 5\%, F) da glicina 10\%, G) valina 5\%, H) histidina $0,15 \%$, I) sulfato de amônio e alumínio $0,30 \%$ e J) floroglucina $0,5 \%$.
A segunda, é que as sementes cristalinas devem possuir extremidades alternando-se com faces planas. As extremidades são alimentadas mais abundantemente que as faces planas, onde a difusão de material é não convergente (Fig.4).

Quando se adiciona à água certa quantidade de um composto anfifílico solúvel uma parte é dissolvida na forma de monômero e outra forma uma monocamada nas interfaces. Na superfície da solução os anfilos estão concentrados nas regiões interfásicas água-ar ou adsorvidos nas sementes cristalinas, comprimidos uns contra os outros numa tentativa de manter as moléculas com um maior número de vizinhos semelhantes (minimizando a área de superfície e a repulsão Forma-se uma película de maior densidade que é um verdadeiro escudo para o resto do líquido. entre os grupos hidrofóbicos e a água) (SALAGER, 1993). 


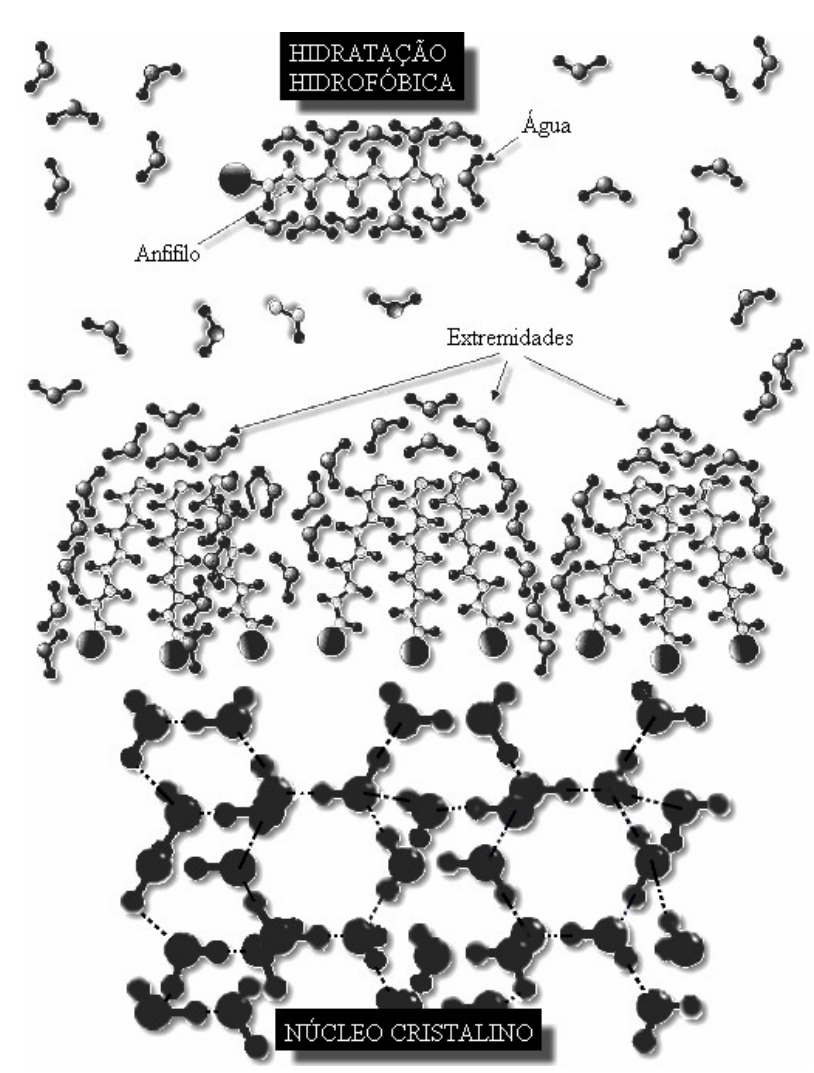

FIGURA 3 - Hidratação hidrofóbica na cauda dos anfifilos adsorvidos nas sementes cristalinas.

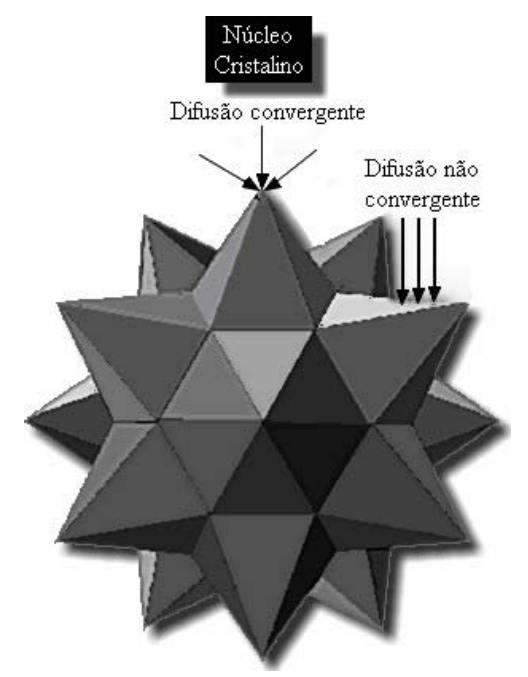

FIGURA 4 - Um cristal sólido limitado por planos com faces estreladas e o exemplo de difusão convergente de material em torno das extremidades e difusão não convergente nas faces.
A diferença natural entre as velocidades de crescimento nas extremidades e nas faces é exagerada pelo processo de difusão, que é evidentemente mais convergente nas extremidades — daí a formação de agulhas, que crescem alongadas (às vezes ramificadas). $\mathrm{O}$ crescimento dos cristais de gelo que se segue em profundidade é mais lento: primeiro, porque são mais fáceis as moléculas se adicionarem aos núcleos inicialmente constituídos na superfície, que formarem novos núcleos no interior da solução; segundo, devido ao fato dos agentes afifílicos serem adsorvidos nas interfaces (água / cristais de gelo), e terceiro (e mais importante), porque depende da diferença do gradiente de temperatura entre o interior e a superfície da solução. O calor de cristalização tem que ser transferido através das camadas sólidas de gelo até a superfície e, finalmente, ser removido pelo ar.

Um maior tempo para uma melhor disposição estrutural seria a justificativa para a observação de que nas camadas inferiores os cristais são mais bem formados que na superfície.

Nas camadas superiores onde é maior a velocidade de arranjo das moléculas, a possibilidade de ocorrer desvios do ideal cristalino é apreciavelmente (às vezes consideravelmente) maior que no seio da solução e está mais sujeito às leis do acaso.

Nas camadas inferiores onde o número de nucléolos cristalinos é menor e não existe a camada surfactante que se estende por toda a superfície, é muito provável que um cristal inicie seu crescimento longe de outro já formado - podendo, assim, crescer livremente seguindo a simetria hexagonal.

\section{Estruturas micelares com eixos radiais curvos}

A região à volta do cristal é menos densa porque o material dissolvido na solução precipitou depositando sobre o centro da arquitetura micelar. Levantou-se a hipótese de que, por vezes, a densidade no centro micelar pode ser tão alta que pode fazê-lo ir ao fundo, curvando o espaço circundante. Alguns monocristais de gelo adjacentes seriam atraídos pela superfície curva invisível, aumentando ainda mais, por peso, a depressão. Esse processo somente seria interrompido quando barrado por outras estruturas cristalinas (iguais, ou não) (Fig.5).

É possível que na solução aquosa formada com o sal sulfato de amônio e alumínio o $\mathrm{Al}^{3+}$ seja cercado por cinco moléculas de amônia formando um íon complexo, isto é $\mathrm{Al}\left(\mathrm{NH}_{3}\right)_{5}{ }^{+2}$. O íon complexo com quinze possibilidades de ligação em ponte nas mais diversas direções, explicaria a as estruturas micélicas esféricas observadas. 


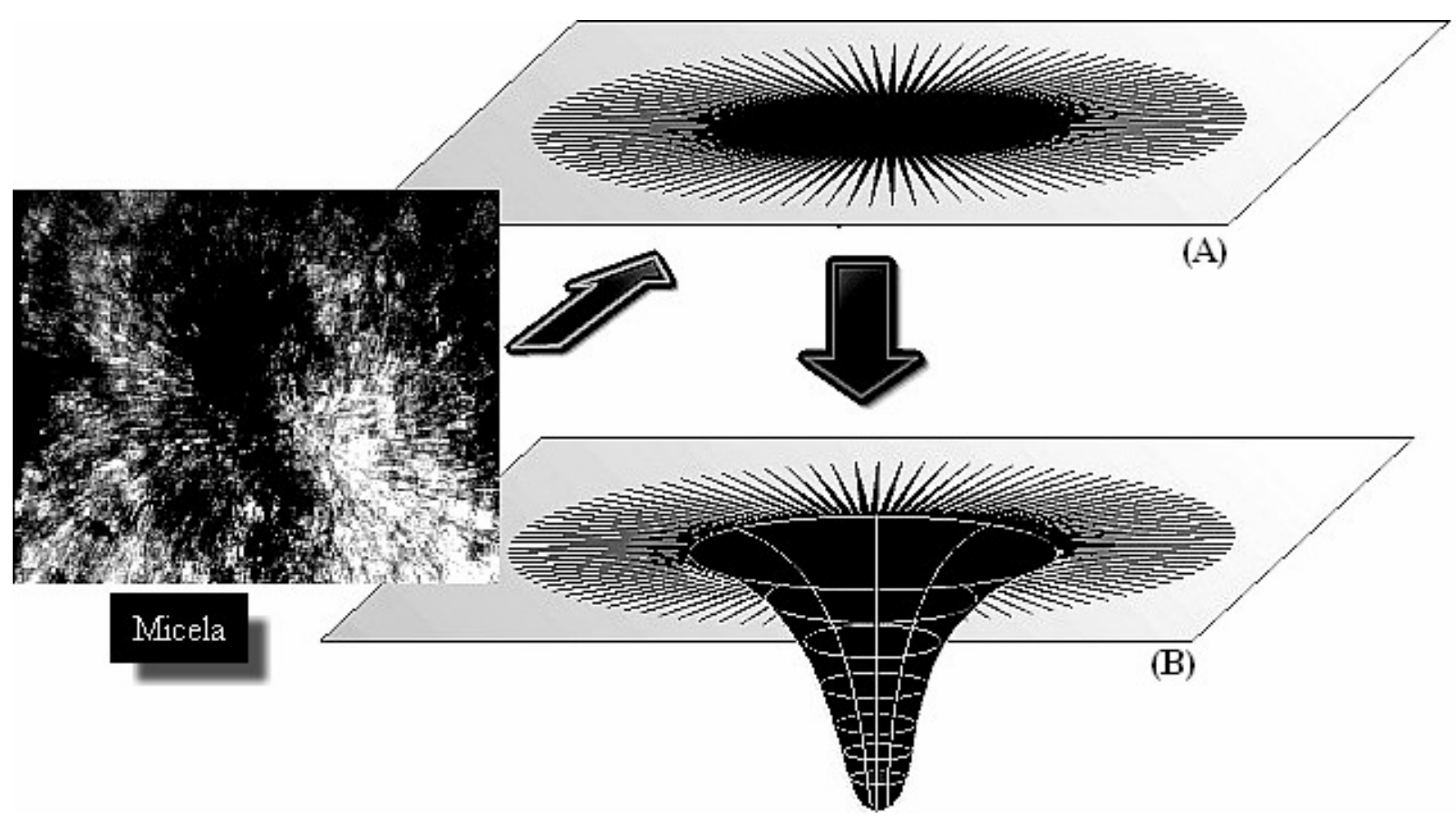

FIGURA 5 - Ilustração mostrando que centros micelares muito densos (a) podem deformar a região circundante, curvando o seu espaço e formar uma estrutura micelar deformada (b) em forma de funil.

É possível que a hidratação hidrofóbica em torno do grupo apolar das substâncias anfifílicas produza extremidades onde a difusão de massa d'água convergente gerem os feixes alongados que deram forma à disposição micelar esférica.

Nas soluções contendo a floroglucina os nucléolos produzidos podem ser sólidos limitados por planos de faces estreladas já que a difusão mássica da água não foi convergente nas faces e assim os crescimentos que se lançaram dos diferentes lados do centro cristalino não formaram agulhas. É possível que possamos usar esse trifenol como crioprotetor no pré-tratamento de tecidos congelados.

\section{CONCLUSÕES}

A alta simetria da estrutura molecular da floroglucina preencheu os requisitos para um bom arranjo na construção cristalina com a água. Seu retículo cristalino regular e arredondado deu oportunidades iguais para o crescimento nas diferentes orientações sem formar grandes ressaltos.

\section{AGRADECIMENTOS}

Agradecimentos às instituições: Coordenação de Aperfeiçoamento de Pessoal de Nível Superior (CAPES), pelo suporte financeiro oferecido e Universidade Federal de Lavras (UFLA), pelo suporte técnico e ensino qualificado. Minha gratidão mais profunda ao Prof. Dr. José Cal-Vidal e a Dra. Clécia da Silva Carneiro pela prestimosa colaboração.

\section{REFERÊNCIAS BIBLIOGRÁFICAS}

CARNEIRO, C. S.; CAL-VIDAL, J. Ice crystal structuring as affected by anphiphilic substances. The Journal of Scanning Microcopies, Mahwah, v. 20, n. 3, p. 244-246, Nov./Dec. 1992.

CARNEIRO, C. S.; CAL-VIDAL, J. Structuring capacity of ice crystal under the influence of sugars with diverse chemical nature. In: INTERNATIONAL SYMPOSIUM ON WATER MANAGEMENT IN THE DESIGN AND DISTRIBUTION OF QUALITY FOODS, 7., 1998, Helsinki. Proceedings... Helsinki: [s.n.], 1998. p. 1-4. 
ECHLIN, P. Low-temperature microscopy and analysis. New York: Plenum, 1992. 539 p.

GARRETT, R. H.; GRISHAM, C. M. Biochemistry. Londres: Saunders College, 1995. 1100 p.

RESENDE, J. V.; CAL-VIDAL, J. Reducing freeze damage in fruits.In: INTERNATIONAL CONGRESS ON ENGINEERING AND FOOD, 7., 1997, Brighton. Proceedings... London: Sheffield Academic, 1997. p. SA1-SA4.
SALAGER, J. L. Surfactantes en solución acuosa. Mérida: Universidad de Los Andes, 1993. (Cuaderno FIRP, 201A).

SILVA, M. L. A. Síntese e caracterização de complexos de $\mathrm{Cu}^{+2} \mathrm{e} \mathrm{VO}^{2+} \mathrm{e} \mathrm{Sn}^{+4}$ com moléculas anfifílicas derivadas de a-aminoácidos propriedades físico-químicas e teste biológico de tensoativos. 1997. Tese (Doutorado em Química) - Universidade Federal de Minas Gerais, Belo Horizonte, 1997. 